\title{
Fluid-Attenuated Inversion Recovery Hyperintensity in Acute Ischemic Stroke May Not Predict Hemorrhagic Transformation
}

\author{
Bruce C.V. Campbell ${ }^{\mathrm{a}, \mathrm{b}}$ Craig Costello ${ }^{\mathrm{a}}$ Søren Christensen ${ }^{\mathrm{b}}$ Martin Ebinger ${ }^{\mathrm{e}}$ \\ Mark W. Parsons $^{d}$ Patricia M. Desmond ${ }^{b}$ P. Alan Barber ${ }^{f}$ Kenneth S. Butcher ${ }^{g}$ \\ Christopher R. Levi ${ }^{d}$ Deidre A. De Silva ${ }^{\text {h }}$ Maarten G. Lansberg ${ }^{i}$ Michael Mlynash ${ }^{i}$ \\ Jean-Marc Olivot ${ }^{i}$ Matus Strakai Roland Bammer ${ }^{i}$ Gregory W. Albers ${ }^{i}$ \\ Geoffrey A. Donnanc Stephen M. Davis a for the EPITHET-DEFUSE Investigators \\ Departments of a Medicine and Neurology, and ${ }^{b}$ Radiology, The Royal Melbourne Hospital, University of \\ Melbourne, ${ }^{c}$ Florey Neuroscience Institutes, University of Melbourne, Parkville, Vic., and ${ }^{\mathrm{d}}$ Department of \\ Neurology and Hunter Medical Research Institute, John Hunter Hospital, University of Newcastle, \\ Newcastle, N.S.W., Australia; ${ }^{e}$ Center for Stroke Research Berlin, Charité-Universitätsmedizin, Berlin, Germany; \\ ${ }^{f}$ Centre for Brain Research, University of Auckland, Auckland, New Zealand; ${ }^{9}$ Faculty of Medicine and Dentistry,

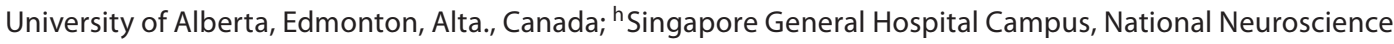 \\ Institute, Singapore, Singapore; iDepartment of Neurology and Neurological Sciences and the Stanford Stroke \\ Center, Stanford University Medical Center, Stanford, Calif., USA
}

\section{Key Words}

Stroke $\cdot$ Tissue plasminogen activator $\cdot$ MRI .

Fluid-attenuated inversion recovery

\begin{abstract}
Background: Fluid-attenuated inversion recovery (FLAIR) hyperintensity within an acute cerebral infarct may reflect delayed onset time and increased risk of hemorrhage after thrombolysis. Given the important implications for clinical practice, we examined the prevalence of FLAIR hyperintensity in patients 3-6 $\mathrm{h}$ from stroke onset and its relationship to parenchymal hematoma (PH). Methods: Baseline DWI and FLAIR imaging with subsequent hemorrhage detection (ECASS criteria) were prospectively obtained in patients 3-6 $\mathrm{h}$ after stroke onset from the pooled EPITHET and DEFUSE trials. FLAIR hyperintensity within the region of the acute DWI lesion was rated qualitatively (dichotomized as
\end{abstract}

visually obvious or subtle (i.e. only visible after careful windowing)) and quantitatively (using relative signal intensity (RSI)). The association of FLAIR hyperintensity with hemorrhage was then tested alongside established predictors (very low cerebral blood volume (VLCBV) and diffusion (DWI) lesion volume) in logistic regression analysis. Results: There were 49 patients with pre-treatment FLAIR imaging (38 received tissue plasminogen activator (tPA), 5 developed PH). FLAIR hyperintensity within the region of acute DWI lesion occurred in 48/49 (98\%) patients, was obvious in 18/49 (37\%) and subtle in 30/49 (61\%). Inter-rater agreement was $92 \%$ $(\kappa=0.82)$. The prevalence of obvious FLAIR hyperintensity did not differ between studies obtained in the 3-4.5 $\mathrm{h}$ and $4.5-6 \mathrm{~h}$ time periods ( $40 \%$ vs. $33 \%, \mathrm{p}=0.77$ ). $\mathrm{PH}$ was poorly predicted by obvious FLAIR hyperintensity (sensitivity $40 \%$, specificity $64 \%$, positive predictive value $11 \%$ ). In univariate logistic regression, VLCBV $(p=0.02)$ and DWI lesion volume $(p=0.03)$ predicted PH but FLAIR lesion volume $(p=0.87)$

\section{KARGER \\ Fax +4161306 1234 \\ E-Mail karger@karger.ch}

() 2011 S. Karger AG, Basel

www.karger.com
Accessible online at: www.karger.com/ced
Bruce C.V. Campbell, FRACP

Department of Neurology, The Royal Melbourne Hospital

Grattan Street

Parkville, VIC 3050 (Australia)

Tel. +61 39342 8448, E-Mail Bruce.Campbell@mh.org.au 
and RSI ( $p=0.11)$ did not. In ordinal logistic regression for hemorrhage grade adjusted for age and baseline stroke severity (NIHSS), increased VLCBV $(p=0.002)$ and DWI lesion volume ( $p=0.003$ ) were associated with hemorrhage but FLAIR lesion volume $(p=0.66)$ and RSI $(p=0.35)$ were not. Conclusions: Visible FLAIR hyperintensity is almost universal 3-6 $\mathrm{h}$ after stroke onset and did not predict subsequent hemorrhage in this dataset. Our findings question the value of excluding patients with FLAIR hyperintensity from reperfusion therapies. Larger studies are required to clarify what implications FLAIR-positive lesions have for patient selection.

Copyright $\odot 2011$ S. Karger AG, Basel

\section{Introduction}

The use of hyperintensity on T2 fluid-attenuated inversion recovery (FLAIR) imaging as a way to select patients for stroke thrombolysis is controversial. The presence or absence of a FLAIR lesion in the region of the acute DWI lesion has been proposed as a potential 'tissue clock' to guide thrombolytic therapy when the time of onset is uncertain [1-3]. The finding of a visible diffusion lesion in the absence of corresponding FLAIR hyperintensity has been suggested to represent a recent onset, potentially treatable, stroke in patients where the time of symptom onset is uncertain. This clinical scenario is common as patients with wake-up and unknown onset time comprise approximately $20 \%$ of stroke presentations and poses a therapeutic dilemma [3-5]. However, there is doubt about the sensitivity of this approach as the prevalence of FLAIR hyperintensity increases rapidly over time and is often seen in patients within the 4.5 -h stroke thrombolysis treatment window [6]. In addition, FLAIR hyperintensity may represent a risk factor for poor response to thrombolysis. A higher risk of hemorrhage has been reported in patients with baseline FLAIR hyperintensity [7], possibly reflecting altered blood brain barrier permeability. We therefore aimed to examine the prevalence of FLAIR hyperintensity in the pooled EPITHET-DEFUSE trials and its relationship to parenchymal hematoma $(\mathrm{PH})$.

\section{Methods}

EPITHET and DEFUSE were prospective, multicenter trials of thrombolysis in acute ischemic stroke patients 3-6 h after symptom onset. Details of the methods have been reported previously $[8,9]$. In brief, EPITHET patients were randomized to IV tissue plasminogen activator (tPA) or placebo whereas all patients in

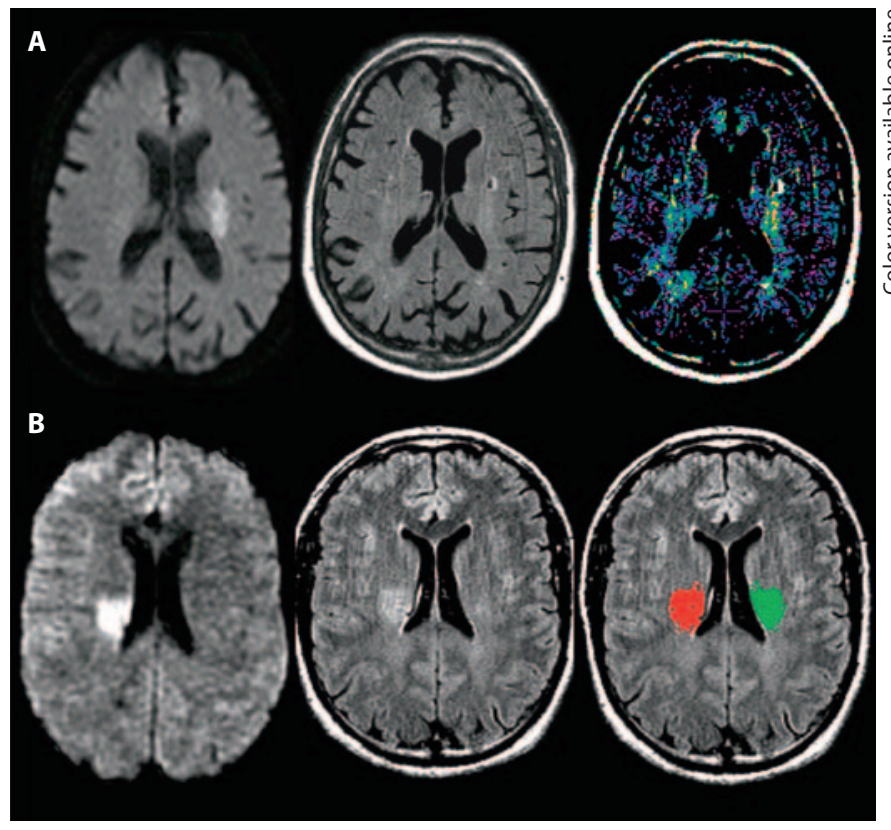

Fig. 1. Examples of DWI and FLAIR hyperintensity. A 'Subtle' FLAIR abnormality not identifiable with standard windowing of FLAIR (middle panel) but apparent after careful windowing and, in this case, application of a color scale (right-hand panel). B 'Obvious' FLAIR hyperintensity visible with standard windowing (middle panel). The right-hand panel shows lesion (red in online version) and mirror (green in online version) FLAIR hyperintensity ROIs used to calculate RSI.

DEFUSE received tPA. Patients had MRI performed before treatment and subsequently to assess for hemorrhagic transformation (HT). In both studies treatment was given without reference to MRI results. The studies were approved by institutional review boards at all centers and informed consent was obtained.

FLAIR imaging was not a mandatory sequence in either study protocol. All available pre-treatment FLAIR images were visually reviewed for the presence of hyperintensity within the infarct by two independent raters. Raters referred to DWI whilst assessing FLAIR abnormalities to maximize sensitivity as described previously [1]. When present, the degree of FLAIR hyperintensity was rated as either visually 'obvious' or 'subtle' (i.e. only visible after careful windowing; fig. 1) as previously described [6]. Inter-rater agreement was assessed using kappa scores. FLAIR hyperintensity was quantitatively assessed using relative signal intensity (RSI). To calculate RSI, the acute FLAIR image was co-registered to the acute DWI image and the DWI lesion outline and its contralateral mirror region were overlaid on the FLAIR. Portions of these regions of interest (ROIs) that did not overly brain (for example sulci) were removed using a cerebrospinal fluid threshold and established leukoaraiosis was manually removed from the ROIs. The ratio of mean signal intensity in the two ROIs (the RSI) was calculated.

HT on MRI or CT was classified using ECASS criteria (hemorrhagic infarction (HI1 and HI2) or PH (PH1 and PH2)) by con- 
sensus of 3 stroke neurologists. Symptomatic HT (sICH) was defined using SITS-MOST criteria [10]. Very low cerebral blood volume (VLCBV) was calculated as previously described [11] using a definition of $\mathrm{CBV}<2.5$ th percentile of normal contralateral brain. The association of FLAIR hyperintensity with $\mathrm{PH}$ was tested in univariate and backwards stepwise multivariate binary logistic regression with age and baseline NIHSS. The association of FLAIR hyperintensity with HT graded as none, HI or PH was also tested in univariate and backwards stepwise multivariate ordinal logistic regression adjusted for age and baseline NIHSS. The same analysis procedures were performed with the established predictors VLCBV and DWI lesion volume [11, 12]. Statistical analysis was performed using Minitab (v16, Minitab Inc., Pennsylvania, USA).

\section{Results}

Fifty-five of 175 patients enrolled in EPITHET and DEFUSE had acute FLAIR imaging, as this was not a standard sequence in many centers. After excluding three patients with no DWI lesion, two with severe motion degradation and one with confluent leukoaraiosis throughout the infarct region, 49 patients were analyzed. Thirtyeight of the 49 patients received $\mathrm{PAA}$, of whom 5 developed $\mathrm{PH}$ (2 PH1 and $3 \mathrm{PH} 2$, including 1 with sICH). Clinical characteristics (including hemorrhage rates) were comparable between the patients with FLAIR imaging and the remainder of the cohort (table 1).

\section{Prevalence of FLAIR Hyperintensity}

FLAIR hyperintensity within the infarct occurred in $48 / 49$ (98\%) patients, and was obvious in $18 / 49$ (37\%) and subtle in 30/49 (61\%). Inter-rater agreement for classifying subtle versus obvious FLAIR hyperintensity was good $(92 \%, \kappa=0.82)$. The prevalence of obvious FLAIR hyperintensity did not differ significantly between the $3-4.5 \mathrm{~h}$ and $4.5-6 \mathrm{~h}$ time periods ( $40 \mathrm{vs.} 33 \%, \mathrm{p}=0.77$ ). Visually obvious FLAIR hyperintensity was associated with larger FLAIR lesions (median 17 vs. $2 \mathrm{ml}, \mathrm{p}<0.001$ ), DWI lesions (median 34 vs. $11 \mathrm{ml}, \mathrm{p}=0.03$ ), and slightly increased FLAIR RSI (RSI, median 1.12 vs. 1.09, $\mathrm{p}=$ 0.007).

\section{Predicting Hemorrhagic Transformation}

PH was poorly predicted by obvious FLAIR hyperintensity. PH occurred in 2/18 (11\%) patients with obvious hyperintensity versus $3 / 31$ (9.7\%) patients with no or subtle hyperintensity. The sensitivity of obvious hyperintensity was therefore $40 \%$, specificity $64 \%$ and positive predictive value $11 \%$. In univariate binary logistic regression for prediction of $\mathrm{PH}$, age, baseline NIHSS, baseline DWI
Table 1. Clinical characteristics of patients $(n=175)$

\begin{tabular}{|c|c|c|c|}
\hline & \multicolumn{2}{|l|}{ Acute FLAIR } & \multirow{2}{*}{$\begin{array}{l}\mathrm{p} \\
\text { value }\end{array}$} \\
\hline & assessable & $\begin{array}{l}\text { not } \\
\text { assessable }\end{array}$ & \\
\hline Number of patients & 49 & 126 & \\
\hline Age, years & $68.3 \pm 16.4$ & $72.4 \pm 12.4$ & 0.23 \\
\hline Male gender & $24(49 \%)$ & $64(51 \%)$ & 0.87 \\
\hline Hypertension & $29(59 \%)$ & $88(70 \%)$ & 0.21 \\
\hline Diabetes & $12(25 \%)$ & $30(24 \%)$ & 0.99 \\
\hline Smoking & $20(41 \%)$ & $48(38 \%)$ & 0.86 \\
\hline Dyslipidemia & $17(35 \%)$ & $42(33 \%)$ & 0.86 \\
\hline Atrial fibrillation & $10(20 \%)$ & $50(40 \%)$ & 0.02 \\
\hline Baseline NIHSS, median & 11 & 12 & \\
\hline IQR & $8-15$ & $8-17$ & 0.15 \\
\hline Acute DWI volume, ml & $34 \pm 42$ & $35 \pm 46$ & 0.47 \\
\hline Received tPA & $38(78 \%)$ & $88(70 \%)$ & 0.45 \\
\hline Time to MRI, min & $262 \pm 53$ & $265 \pm 44$ & 0.86 \\
\hline Time to treatment, min & $309 \pm 44$ & $308 \pm 44$ & 0.86 \\
\hline Symptomatic hemorrhage & $1(2 \%)$ & $7(6 \%)$ & 0.44 \\
\hline $\mathrm{PH}$ & $5(10 \%)$ & $20(16 \%)$ & 0.35 \\
\hline
\end{tabular}

Data represent means \pm SD unless otherwise indicated.

Table 2. Predicting parenchymal hematoma $(\mathrm{PH})$

\begin{tabular}{lllll}
\hline & \multicolumn{3}{l}{$\begin{array}{l}\text { Univariate binary logistic } \\
\text { regression }\end{array}$} & $\begin{array}{l}\text { ROC } \\
\text { AUC }\end{array}$ \\
\cline { 2 - 4 } & OR & $95 \%$ CI & p value & \\
\hline Visually obvious & 1.17 & $0.18-7.7$ & 0.87 & N/A \\
FLAIR intensity, RSI & $0.22^{*}$ & $0.03-1.4$ & 0.11 & 0.30 \\
FLAIR volume, ml & 1.00 & $0.97-1.0$ & 0.87 & 0.43 \\
DWI volume, ml & 1.02 & $1.0-1.04$ & $\mathbf{0 . 0 3}$ & 0.92 \\
VLCBV volume, ml & 10.9 & $1.5-81$ & $\mathbf{0 . 0 2}$ & 0.91 \\
\hline
\end{tabular}

* OR per 0.1 shift in RSI (i.e. upper estimate of increased PH risk is 1.4).

lesion volume and VLCBV were significant predictors but FLAIR RSI or volume were not (table 2). The 95\% confidence interval for the odds ratio (OR) indicated that the risk of $\mathrm{PH}$ incurred by a 0.1 increase in RSI was up to 1.4 - a relatively small effect size given the range of RSI measurements using this technique (1.0-1.2). Univariate ordinal logistic regression produced the same pattern of results (not shown). In multivariate ordinal logistic re- 
gression for hemorrhage grade, VLCBV $(\mathrm{p}=0.002)$ and DWI infarct volume $(\mathrm{p}=0.003)$ each remained significant after adjustment for age and baseline NIHSS but FLAIR lesion volume $(p=0.66)$ and RSI $(p=0.35)$ were not. VLCBV and DWI were also significant predictors of $\mathrm{PH}$ in the 38 patients who received tPA.

\section{Discussion}

This study has demonstrated the almost universal presence of FLAIR hyperintensity beyond $3 \mathrm{~h}$ from stroke onset. This implies that many patients within the currently accepted 4.5 -h thrombolytic treatment window [13] have hyperintense FLAIR lesions within the acute infarct. It is therefore difficult to justify using the presence of ischemic lesions on FLAIR imaging to exclude patients from thrombolytic therapy when onset time is uncertain. Although the degree of FLAIR hyperintensity might imply more severe ischemia, this did not translate to an increased risk of hemorrhage in this study. Recent studies have shown that FLAIR hyperintensity does not influence clinical response to tPA [14] and that DWI lesion reversal is uncommon $[15,16]$. The results of the present study, taken in conjunction with these earlier findings, raise questions about the clinical utility of acute FLAIR imaging.

The prevalence of FLAIR hyperintensity was higher in this study than the previously reported $65-93 \%$ of patients in studies where DWI was used as a reference $[1,6]$. Our data, consistent with those previous reports, showed that visual detection of FLAIR hyperintensity is more likely in larger infarcts. The larger DWI lesions in this study are probably responsible for the observed difference in prevalence.

The severity (qualitative or quantitative) of FLAIR hyperintensity did not predict hemorrhage risk in the 3-6 h treatment window. This contrasts with an earlier study in which patients were imaged at $0-6 \mathrm{~h}$ after symptom onset [7]. The prevalence of visually evident FLAIR hyperintensity in that study was $30 \%$, although the precise definition of hyperintensity was not specified and patients with large FLAIR lesions matching the diffusion lesion were excluded from the study. This difference in apparent hemorrhage risk may reflect the proportion of $0-3 \mathrm{~h}$ patients in the earlier study. Before $3 \mathrm{~h}$, FLAIR is more frequently negative [1]. It is possible that the development of obvious FLAIR hyperintensity within $3 \mathrm{~h}$ may represent more intense ischemia and greater risk of $\mathrm{HT}$ in this early subset of patients.
The main limitation of our study is the relatively small sample size. Despite this, both DWI lesion volume and VLCBV remained significant predictors of hemorrhage. We cannot exclude the possibility that FLAIR hyperintensity has some predictive utility for HT in acute stroke, however there are clearly more potent imaging parameters readily available in clinical practice.

The high prevalence of acute FLAIR hyperintensity within the infarct raises the issue of how well these changes can be distinguished from chronic hyperintensities due to leukoaraiosis. The lower signal intensity of acute changes and morphology matching the DWI lesion generally allow differentiation unless there is major confluent leukoaraiosis where distinguishing these two processes is not possible. We excluded the single patient with confluent leukoaraiosis in the infarct region from this analysis. Nonetheless it remains possible that our attempts to manually exclude leukoaraiosis from the RSI calculation were incompletely successful. This is, however, a further argument against the utility of this technique for predicting treatment response in clinical practice.

Some centers currently use FLAIR hyperintensity as an exclusion from thrombolysis when treating outside the conventional time window. Our findings question whether this may result in unnecessary exclusion of patients who could benefit from treatment. Larger studies are required to clarify what implications FLAIR positive lesions have for patient selection.

\section{Acknowledgements}

The EPITHET study was supported by the National Health and Medical Research Council of Australia, National Stroke Foundation and National Heart Foundation of Australia. The DEFUSE study was funded by National Institutes of Health (NIH) grants RO1 NS39325, Principal Investigator, Gregory W. Albers; K24 NS044848, Principal Investigator, Gregory W. Albers; and K23 NS051372, Principal Investigator Maarten G. Lansberg.

tPA was supplied at no charge by Boehringer Ingelheim (Australia, New Zealand and European sites) and Genentech (USA and Canada sites). Neither Boehringer Ingelheim, Genentech nor the NIH played a role in the design and the conduct of the studies; collection, management, analysis, and interpretation of the data; or preparation or approval of the manuscript.

Bruce Campbell is supported by a National Health and Medical Research Council of Australia postgraduate scholarship 567156, the Heart Foundation of Australia, a Cardiovascular Lipid Australia grant, the Royal Melbourne Hospital Neuroscience Foundation and Victor Hurley Fund. Roland Bammer receives support from NIH grant R01 EB002711. 


\section{References}

-1 Thomalla G, Rossbach P, Rosenkranz M, Siemonsen S, Krutzelmann A, Fiehler J, Gerloff C: Negative fluid-attenuated inversion recovery imaging identifies acute ischemic stroke at 3 hours or less. Ann Neurol 2009; 65:724-732.

$\checkmark 2$ Aoki J, Kimura K, Iguchi Y, Shibazaki K, Iwanaga T, Watanabe M, Kobayashi K, Sakai K, Sakamoto Y: Intravenous thrombolysis based on diffusion-weighted imaging and fluid-attenuated inversion recovery mismatch in acute stroke patients with unknown onset time. Cerebrovasc Dis 2011;31: 435-441.

>3 Cho AH, Sohn SI, Han MK, Lee DH, Kim JS, Choi CG, Sohn CH, Kwon SU, Suh DC, Kim SJ, Bae HJ, Kang DW: Safety and efficacy of MRI-based thrombolysis in unclear-onset stroke. A preliminary report. Cerebrovasc Dis 2008;25:572-579.

$\checkmark 4$ Barreto AD, Martin-Schild S, Hallevi H, Morales MM, Abraham AT, Gonzales NR, Illoh K, Grotta JC, Savitz SI: Thrombolytic therapy for patients who wake-up with stroke. Stroke 2009;40:827-832.

$\checkmark 5$ Silva GS, Lima FO, Camargo EC, Smith WS, Singhal AB, Greer DM, Ay H, Lev MH, Harris GJ, Halpern EF, Sonni S, Koroshetz W, Furie KL: Wake-up stroke: Clinical and neuroimaging characteristics. Cerebrovasc Dis 2010;29:336-342.

6 Ebinger M, Galinovic I, Rozanski M, Brunecker P, Endres M, Fiebach JB: Fluid-attenuated inversion recovery evolution within 12 hours from stroke onset: a reliable tissue clock? Stroke 2010;41:250-255.
Cho AH, Kim JS, Kim SJ, Yun SC, Choi CG, Kim HR, Kwon SU, Lee DH, Kim EK, Suh DC, Kang DW: Focal fluid-attenuated inversion recovery hyperintensity within acute diffusion-weighted imaging lesions is associated with symptomatic intracerebral hemorrhage after thrombolysis. Stroke 2008;39: 3424-3426.

8 Davis SM, Donnan GA, Parsons MW, Levi C, Butcher KS, Peeters A, Barber PA, Bladin C, De Silva DA, Byrnes G, Chalk JB, Fink JN, Kimber TE, Schultz D, Hand PJ, Frayne J Hankey G, Muir K, Gerraty R, Tress BM, Desmond PM: Effects of alteplase beyond $3 \mathrm{~h}$ after stroke in the echoplanar imaging thrombolytic evaluation trial (EPITHET): a placebo-controlled randomised trial. Lancet Neurol 2008;7:299-309.

$\checkmark 9$ Albers GW, Thijs VN, Wechsler L, Kemp S, Schlaug G, Skalabrin E, Bammer R, Kakuda W, Lansberg MG, Shuaib A, Coplin W, Hamilton S, Moseley M, Marks MP: Magnetic resonance imaging profiles predict clinical response to early reperfusion: the diffusion and perfusion imaging evaluation for understanding stroke evolution (DEFUSE) study. Ann Neurol 2006;60:508-517.

10 Wahlgren N, Ahmed N, Davalos A, Ford GA, Grond M, Hacke W, Hennerici MG, Kaste M, Kuelkens S, Larrue V, Lees KR, Roine RO, Soinne L, Toni D, Vanhooren G: Thrombolysis with alteplase for acute ischaemic stroke in the safe implementation of thrombolysis in stroke-monitoring study (SITS-MOST): an observational study. Lancet 2007;369: 275-282.

-11 Campbell BC, Christensen S, Butcher KS, Gordon I, Parsons MW, Desmond PM, Barber PA, Levi CR, Bladin CF, De Silva DA, Donnan GA, Davis SM: Regional very low cerebral blood volume predicts hemorrhagic transformation better than diffusionweighted imaging volume and thresholded apparent diffusion coefficient in acute ischemic stroke. Stroke 2010;41:82-88.
12 Singer OC, Humpich MC, Fiehler J, Albers GW, Lansberg MG, Kastrup A, Rovira A, Liebeskind DS, Gass A, Rosso C, Derex L, Kim JS, Neumann-Haefelin T: Risk for symptomatic intracerebral hemorrhage after thrombolysis assessed by diffusion-weighted magnetic resonance imaging. Ann Neurol 2008;63:52-60.

13 Lees KR, Bluhmki E, von Kummer R, Brott TG, Toni D, Grotta JC, Albers GW, Kaste M, Marler JR, Hamilton SA, Tilley BC, Davis SM, Donnan GA, Hacke W: Time to treatment with intravenous alteplase and outcome in stroke: an updated pooled analysis of ECASS, ATLANTIS, NINDS, and EPITHET trials. Lancet 2010;375:1695-1703.

14 Ebinger M, Ostwaldt AC, Galinovic I, Rozanski M, Brunecker P, Nolte $\mathrm{CH}$, Endres M, Fiebach JB: Clinical and radiological courses do not differ between fluid-attenuated inversion recovery-positive and negative patients with stroke after thrombolysis. Stroke 2010; 41:1823-1825.

15 Chemmanam T, Campbell BCV, Christensen S, Nagakane Y, Desmond PM, Bladin CF, Parsons MW, Levi CR, Barber PA, Donnan GA, Davis SM: Ischemic diffusion lesion reversal is uncommon and rarely alters perfusion-diffusion mismatch. Neurology 2010; 75:1040-1047.

16 Campbell BCV, Purushotham A, Christensen S, Desmond P, Nagakane Y, Parsons MW, Lansberg MG, Mlynash M, Straka M, De Silva DA, Olivot JM, Bammer R, Albers GW, Donnan GA, Davis SM: The infarct core is well represented by the acute diffusion lesion: sustained reversal is infrequent. J Cereb Blood Flow Metab 2011, E-pub ahead of print. 